\title{
ESTADO, DERECHO Y ESTUDIOS DE GÉNERO
}

\author{
JULIA SEVILLA / ASUNCIÓN VENTURA \\ (Universidad de Valencia / Universidad Jaume I)
}

\section{INVESTIGACIONES, GÉNERO Y DERECHO: ESTADO DE LA CUESTIÓN}

No hace mucho hubiera sido impensable la relación entre estos tres elementos: Estado, Derecho y Estudios de Género y ello por la sencilla razón de que tanto el Estado como el Derecho formaban parte de la construcción hecha en nombre de toda la humanidad aunque el resultado fuera sólo para una parte. Bien es cierto que esa parte tampoco era igual para el 50\% masculino de la misma pero sí era una parte de base más amplia y conceptuada hablando para todos los hombres y esa premisa es tanto más ardua cuando estamos hablando de dos elementos que justifican su existencia en el logro de la igualdad. El derecho, que debería ser un factor de nivelación social y, por supuesto, de igualdad, perpetúa, por el contrario, la consideración de las mujeres como objeto de estudios y no como actoras sociales. Como afirma Hernes «el género ha sido siempre un principio básico en la organización de las sociedades, pero rara vez ha sido tratado como concepto básico analítico en las ciencias sociales» ${ }^{1}$. En el derecho ha primado más su vertiente estabilizadora, la consecución del orden social, que la idea de progreso que se incorpora, casi siempre, en procesos revolucionarios $y$, por tanto, transgresores de las normas. Por ello, cuando el Estado incorpora la idea social y democrática, como lo hace la Constitución Española de 1978, promueve necesariamente un cambio normativo. Así ocurrió en España a partir de las primeras elecciones democráticas de 15 de junio de 1977. Las Cortes que surgieron de las mismas hubieron de abordar, no sólo la tarea constituyente, sino una primera reforma legislativa que afectó primordialmente al contenido del derecho civil.

A partir de la promulgación de la constitución de 1978 se produce una importante actividad legislativa en la medida en que hay que modificar el ordenamiento jurídico para adaptarlo a la nueva constitución; paralelamente se produ-

1. HERNES, H.M: "El poder de las Mujeres y el Estado de Bienestar», Vindicación Feminista, 1.990, p.22. 
ce una actividad investigadora en las universidades españolas en el ámbito del derecho, que si bien es cierto que no se puede comparar con otras materias (historia, etc.) lo cierto es que se vislumbra un cierto interés en las investigaciones de derecho en las que las mujeres tienen un cierto protagonismo como sujetos investigadoras y como objeto de estudio. Hasta los años 80 la investigación, y en general toda la actividad académica en el ámbito del derecho, tiene centrado su interés en temas en los que las mujeres han estado excluidas o han participado de forma muy escasa, pero la promulgación de la Constitución Española de 1978 y la instauración del principio de igualdad favorecen el estudio del derecho en relación con el grupo de las mujeres. La creación de un nuevo orden político que implanta un sistema de libertades posibilita la normalización social del movimiento feminista y su difusión, apareciendo lo que se denomina el feminismo académico ${ }^{2}$ que inicia este tipo investigaciones y sitúa a las mujeres como sujeto de las mismas. Estas investigaciones, en sus inicios, están marcadas por un fuerte carácter interdisciplinar, sirviendo la igualdad como vehículo facilitador y nexo de unión entre las distintas disciplinas y el derecho. Pasar de un sistema autoritario a un sistema democrático implica que la desigualdad de las mujeres con respecto a los hombres se visualiza, al menos la desigualdad recogida en las normas o desigualdad formal, y esta nueva situación abre muchas posibilidades al estudio y la investigación. Por supuesto no nos referimos a las desigualdades ocultas que resultan muy difíciles de detectar.

Esta novedad, para ser mas exactos, se circunscribía al Estado Español dado que en el resto de los países occidentales las investigaciones de género eran ya un hecho y, dependiendo de los diferentes países, estaban bastante consolidadas. El profesorado de las universidades españolas conocía, aunque en ocasiones por referencia, toda la problemática generada en EE.UU alrededor de la affirmative action $y$, en general, el desarrollo del derecho anglosajón en esta materia ${ }^{3}$.

También en el ámbito del derecho Comunitario se habían desarrollado algunas acciones positivas para las mujeres; en realidad, es en la década de los

2. La evolución del movimiento feminista en España dio como resultado la aparición de una gran cantidad de grupos dentro del propio movimiento que, de alguna manera, vincularon su profesión con la militancia feminista y así aparecieron, sobre todo en el ámbito universitario, grupos de investigación formados por profesoras que pertenecían al movimiento femista. Hecho que fue posible gracias al cambio político institucionalizado con la promulgación de la Constitución de 1978 que transformó el Estado en un sistema democrático. Las mujeres podían desde cualquiera de las posiciones sociales que desempeñaran agruparse para analizar, reivindicar, investigar desde la perspectiva feminista, surgiendo así lo que se ha venido a denominar feminismo sectorial, académico, institucional etc. En este mismo sentido se pronuncian algunas autoras como Elena GRAU BIOSCA en «El movimiento de mujeres en el Estado español. 1965-1990», en: Historia de las mujeres. El siglo XX, Madrid, Taurus, 1993, p. 680.

3. En 1986 se publicó una obra de referencia obligada en esta materia de los profesores M. RODRÍGUEZ- PIÑEIRO y M.F. FERNANDEZ: Igualdad y discriminación, Tecnos, Madrid, 1986. El derecho antidiscriminatorio que se ha desarrollado en Europa tiene una clara influencia de la doctrina y el derecho anglosajón y en concreto la experiencia de EEUU. En este entido se pronuncian varias autoras, entre otras M. ANGELES BARRERE UNZUETA: Discriminación, derecho antidiscriminatorio y acción positiva en favor de las mujeres, Cuadernos Cívitas, Madrid, 1997. 
setenta cuando la Unión Europea se compromete más firmemente en materia de igualdad de oportunidades en el ámbito de su competencia, fundamentalmente en lo que respecta al derecho del trabajo y comienza a dictar normas, fundamentalmente Directivas, que podemos denominar bloque normativo en materia de igualdad.

El ámbito jurídico-político ha sido y sigue siendo especialmente reacio a estos temas en la medida que la propia creación del estado y su ordenamiento jurídico ha sido creado y configurado por los varones con exclusión de las muje$\mathrm{res}^{4}$. A esto se añade la presencia mayoritaria de profesores varones en las facultades de derecho, siendo además varones los que conforman la dirección de las escuelas más influyentes que en definitiva van a marcar las líneas de actuación en las respectivas áreas del derecho, y desde luego no está en su preocupación, al menos de forma importante, la problemática de las mujeres.

Otro de los factores que influye en el escaso tratamiento de estos temas en el ámbito académico es la escasa consideración científica que se atribuye a los estudios de género, aunque existen diferencias de tratamiento en relación al tema de las mujeres, de unas ciencias a otras, en casi todas ellas se da una constante tal y como señalan Edurne Uriarte y Aranxa Elizondo ${ }^{5}$ todo tema relacionado con las mujeres ocupa automáticamente un lugar secundario al igual que la posición que estas mantienen en la sociedad. Las autoras añaden otro de los aspectos que contribuye, de forma importante, a mantener una connotación negativa y que resulta de una gran eficacia: que las investigaciones sobre mujeres están imbuidas de ideología feminista que, a pesar de estar muy extendida y ser muy conocida, sigue teniendo una imagen muy negativa en nuestra sociedad.

\section{II.- EL DERECHO DEL ESTADO: UNA REVISIÓN FEMINISTA}

\section{1.- Teoría feminista}

Para hablar de la perspectiva de género en el derecho es preciso hacer referencia a las teorías feministas, que son las que han cuestionado el enfoque liberal sobre el que se ha fundamentado la norma, partiendo de una concepción de la igualdad formal y de un derecho cuyo sujeto es el individuo considerado aisladamente, sin tener en cuenta sus condiciones materiales, y que además se identifica con los valores masculinos.

Existe en la actualidad un gran número de tendencias dentro del feminismo y por ello resulta de una cierta complejidad distinguir grupos o tendencias. Sin

4. LUCAS VERDÚ, P.: «El valor constitucional de la igualdad y la condición femenina», en Revista de Política Comparada, 1981-82, 27-49. El profesor analiza la repercusión del principio de igualdad en la situación de desigualdad de las mujeres y señala el caracter masculino del Estado y de su ordenamiento preconstitucional, lo que le lleva a afirmar que: «... Ideológica, institucional y estructuralmente el mundo jurídico político ha sido creado, configurado e impulsado por los varones con exclusión, aminorada con el paso del tiempo, de las mujeres.» (p. 28).

5. Edurne URIARTE y Aranxa ELIZONDO (coordinadoras): Mujeres en politica, Ariel, Barcelona, 1997, p.17. 
embargo parece existir un cierto consenso alrededor de la existencia de tres grandes tendencias ${ }^{6}$.

La teoría feminista liberal que participa de la teoría general del pensamiento liberal, defiende una concepción individualista de la persona que aspira a realizar los valores de dignidad, igualdad, autonomía y autorrealización individual. La subordinación de las mujeres, de acuerdo con este planteamiento, se debe a la injusta discriminación, legal y de otros tipos, que las privan del derecho de la autorregulación y la búsqueda de su propio interés. Es necesario que la norma proteja el derecho que tienen las mujeres en la misma medida que protege a los hombres y para ello se requiere que el derecho tenga un tratamiento igual para ámbos sexos, en definitiva un derecho que ha de considerarse idéntico al de los hombres.

El feminismo de la igualdad no puede entenderse como un pensamiento monolítico y, dentro de él, es necesario establecer matizaciones que revisten cierto interés desde el punto de vista jurídico y distinguir entre aquellas posiciones que se podrían adscribir a planteamientos estrictamente liberales que propugnan una regulación estrictamente formal de la igualdad -esto es, que las leyes no establezcan diferencias por razón de sexo- y aquellas otras que cuestionan la igualdad formal y plantean la necesidad de establecer acciones positivas en las normas no solamente en el ámbito considerado público sino también en el privado y exigen que tanto los hombres como las mujeres compartan el espacio público y el privado.

El feminismo marxista y el socialista, de acuerdo a lo que plantea C. Castell, comparten la misma noción de la naturaleza humana: «algo históricamente creado mediante la interrelación dialéctica entre la biología , la sociedad humana y el entorno físico, una interrelación mediada por el trabajo humano o práxis» ${ }^{7}$.

No obstante, las feministas socialistas influenciadas por el denominado feminismo radical, al menos en el caso de Estados Unidos, y apartándose en gran medida del planteamiento estrictamente marxista, sostienen que la opresión de las mujeres procede de dos factores combinados: el patriarcado y el capitalismo. Éste planteamiento incorpora en el análisis de la igualdad aspectos como la vida privada, diferenciándose claramente de las posiciones estrictamente liberales que limitan la intervención del estado al ámbito de lo público.

Dentro de esta posición se pueden situar las posiciones feministas que radicalizan el paradigma de la igualdad establecido en la ilustración, reclamando la inclusión de las mujeres en el universalismo igualitario y proponen la necesidad de adoptar medidas fácticas y legales en todos los ámbitos en los que existe desigualdad entre hombres y mujeres o son susceptibles de generarla ${ }^{8}$.

6. CASTELLS, C.: Perspectivas feministas en teoría politica, Barcelona, Paidos, 1996 ; SUÁREZ LLANOS, M. L.: Teoría feminista, politica y derecho, Madrid, Dykinson, 2002.

7. CASTELLS, C: Perspectivas...op cit., p.15

8. En el ámbito internacional en esta posición se pòdría situar a Tove Stang Dahl, aunque algunas autoras, como Leonor Suárez Llanos la sitúan en la concepción liberal del derecho. En el ámbito de nuestro país en esta segunda tendencia se puede situar a la profesora Julia Sevilla. 
La vinculación entre feminismo e Ilustración en nuestro país, podemos atribuirla a la filosofa Celia Amoros; ésta señala que, a pesar de que en algunos ámbitos se olvida el pensamiento feminista, en realidad el feminismo como cuerpo coherente de vindicaciones sólo pudo articularse a partir de las premisas ilustradas, radicalizando el discurso de este nuevo constructo que en realidad es el que representa los ideales emancipatorios. El feminismo ve la Ilustración desde una perspectiva privilegiada dado que puede captar el juego lógico-ideológico de la nueva concepción de la universalidad en uno de sus aspectos más críticos. Los problemas que tienen las vindicaciones del género-sexo femenino son el test que comprueba en qué medida la matriz ilustrada desarrolla o no de modo coherente sus propias posibilidades emancipatorias.

El feminismo de la diferencia parte del fracaso de la modernidad y no quiere participar de esta derrota ni del modelo masculino que ha interiorizado las normas como sujeto con carácter universal; la igualdad buscada por el feminismo de la igualdad representa lo unidimensional mientras que el feminismo de la diferencia representa la variedad y la multiplicidad de la vida?

Dentro del feminismo de la diferencia cabría señalar diferentes tendencias y así se habla del feminismo cultural, feminismo de la diferencia de base psicológica, el feminismo radical y el feminismo posmoderno ${ }^{10}$.

A pesar de la diversidad de tendencias nos referiremos al feminismo radical y al posmoderno por tener una mayor relación con este trabajo en la medida que cuestionan más directamente los parámetros sobre los que se sustenta el orden jurídico.

El feminismo radical surge a finales de los años sesenta con inspiración parcialmente marxista. Pese a la gran heterogeneidad de su pensamiento, se podían señalar algunas coincidencias: a) la reflexión sistemática sobre la relevancia política de la biología reproductiva humana; b) la consideración de que la biología femenina es básica para la división sexual del trabajo en la que arraiga la subordinación de la mujer y c) el papel relevante que se otorga a la cultura y a la socialización porque la mujer se hace y no nace. En definitiva la biología entendida bien como problema bien como solución desempeña un papel clave. Consideran que la clave de la discriminación de las mujeres está en el patriarcado, un conflicto sexual transhistórico que los hombres han resuelto hasta el momento a su favor controlando los cuerpos, la sexualidad y los procesos reproductivos de las mujeres.

El feminismo posmoderno se identifica con los postulados filosóficos de la posmodernidad- antiilustrada propugnando una feminidad alternativa no patriarcal. La valoración de la identidad femenina -basada en sus diferentes modalidades, en la experiencia del cuerpo asexuado y la forma como esta configuraría una inserción en lo real que sería por una parte compartida por todo

9. LONZI, Carla: Escupamos sobre Hegel, 1981.

10. Esta clasificación del feminismo de la diferencia puede encontrarse en Leonor SUÁREZ LLANOS, op. cit., p.88 
el colectivo femenino y, por otra, resultaría cuasi-ontológicamente diferente a la masculina-, la obsesión por su no contaminación con esta última, así como su promoción a la plataforma crítico-subversiva de la cultura patriarcal, son determinantes en esta orientación del feminismo, con todas las -numerosas- variantes que se pueden establecer ${ }^{11}$.

Estas tendencias (tal como señala Carme Castell) en los últimos años han evolucionado en un sentido convergente y ello permite evitar el riesgo del reduccionismo, las desigualdades no tienen una sola causa ni una única solución separada de otras desigualdades de base estructural.

\section{Valores constitucionales}

El Estado, a través del derecho, interviene en los asuntos públicos, de los que la mujer ha sido excluida por tener un sexo diferente que la incapacita para el desarrollo de las actividades públicas. El derecho, en un primer momento, prohíbe la participación de las mujeres, atendiendo a su inferior capacidad, producida directamente por tener un sexo diferente al sexo masculino que es el que reúne las condiciones suficientes de capacidad ${ }^{12}$ para ostentar el poder y por tanto dictar normas.

El estado a través del derecho establece aquellos mecanismos que garantizan la intimidad en aquellos espacios considerados como de libertad para el varón en su vida privada ${ }^{13}$ que se desarrolla fundamentalmente en el domicilio considerado por otra parte como el santuario de la autonomía individual .

El Estado relega a la mujer a desarrollar todos los aspectos de su vida en ese espacio de libertad varonil, fuera de toda actividad social, sometida al poder masculino de acuerdo con las leyes civiles. Su papel será el de mero instrumento que permitirá al varón realizar el valor máximo que esa sociedad considera como tal, la libertad.

Las constituciones, de acuerdo con esos postulados, surgen sin la intervención de las mujeres y los valores en ellas incorporados responden a la cultura de la sociedad en la que nacen cuyo sujeto político y jurídico es el hombre; así los valores de libertad, igualdad y propiedad se identifican con valores masculinos.

11. AMORÓS, Celia, Tiempos de feminismo, Madrid. Cátedra 1997.

12. Olsen FRANCES aborda la cuestión de los dualismos, el hombre es racional y la mujer representa la emoción.

13. Esta concepción de libertad cuyo origen se sitúa en el argumento que B.CONSTANT establece en De la liberté des anciens comparée a celle des modernes, discours prononcé a l'Athée Royal de Paris, en Escritos Politicos, Madrid, Centro de Estudios Políticos, 1989. Tal y como señala el profesor Joaquín Martín, La democracia y el tribunal constitucional. Valencia. Edicions Alfons el Magnànim, 1996. Teoría de la democracia en la Jurisprudencia del Tribunal Constitucional, en la teoría de Constant se aprecia, por una parte, esa independencia individual "... Para los modernos, el hombre lo es en cuanto tal, tienen dignidad propia y, en este sentido, le pertenece un ámbito vital en el que poder desarrollarse y desarrollar sus capacidades. Se trata de un ámbito de autonomía individual en el que nadie puede interferir, en el que, por tanto, el Estado no puede entrar. La libertad, pues, son las garantías de protección frente a las injerencias del Estado en ese ámbito de autonomia individual.», p. 176. 
Las constituciones, teóricamente, deben arbitrar los medios necesarios para alcanzar esos valores, esas posibilidades emancipatorias que representa el Estado liberal que excluye a las mujeres e incluso justifica dicha exclusión en una circunstancia tan peregrina para el paradigma ilustrado como es el sexo, cuando en realidad el fundamento de la ilustración y del hombre es la razón. La mujer es relegada al ámbito privado donde los tentáculos del poder no pueden llegar, por expresa voluntad estatal reflejada en la constitución. La obra humana a la que se remiten los valores está construida sin las mujeres.

El origen de estos valores y de la sociedad en la que surgen se sitúan en un ámbito exclusivamente masculino ${ }^{14}$. Tanto en lo que respecta a su elaboración teórico-jurídica como en su aplicación practica, sólo los hombres son sujetos de esas normas.

El feminismo, desde posiciones diferentes, ha criticado los valores sobre los que se sustenta el estado moderno, entendiendo que estos valores se identifican o responden a comportamientos imputables a una sola parte del género humano ${ }^{15}$.

La teoría feminista del derecho ${ }^{16}$, en contra de las posiciones que identifican el liberalismo con la experiencia subjetiva de los varones, afirma que las mujeres son diferentes a los hombres y que este hecho es relevante. Sin embargo, la dificultad reside en determinar qué aspectos de la diferencia entre el hombre y la mujer son relevantes para el derecho. A raíz del estudio realizado por Carol Gilligan ${ }^{17}$, se abre un abanico de posibilidades; la autora, en base a sus

14. CARRERAS, M.: Aproximación a la Jurisprudencia Feminista, Excmo. Ayuntamiento de Alcalá de Henares. En este sentido señala: «La condición existencial de la libertad determina los valores propios de la concepción liberal. Como todos somos libres por igual, las instancias de poder deben respetar nuestra libertad como individuos. El predominio del liberalismo en nuestro ámbito cultural ha erigido a la autonomía en el valor oficial que a su vez se funda en la separación material y física del individuo frente a los demás: la separación del otro me igualdad, constituyen en conjunto lo que podríamos llamar la cumbre de la experiencia subjetiva de la separación «(p.106)

15. CARRERAS, M.: ibíd., p.109. Frente a esta experiencia subjetiva de la separación surge la tesis de la conexión que mantiene: «... que las mujeres están, de facto o potencialmente, capacitadas para entroncar materialmente con otra vida humana, mientras que los hombres no. Este hecho tiene consecuencias existenciales, pues, mientras en el caso de los hombres puede ser cierto que el individuo es anterior a la colectividad, esto no procede en el caso de las mujeres.»

16. Conjunto de teorías y autoras vinculadas al movimiento feminista que desde los años 70 inician estudios acerca de la teoría del derecho; dos grupos: Critica Legal Studis y Feminist Jurisprudence, cuestionan la validez de la teoría del derecho como portadora de valores universales. La mención a estas dos corrientes, en el libro de M. CARRERAS Aproximación a la Jurisprudencia Feminista..(op. cit), en el que analiza sus diferencias y similitudes junto con el análisis de Feminist Jurisprudence que realiza J.A. GARCIA AMADO en "iTienen sexo las normas? Temas y problemas de la teoría feminista del Derecho", en Anuario de Filosofía del Derecho, IX, 1992, pp. 12-42, ponen de manifiesto el interés de estos movimientos por desenmascarar la ideología existente en el derecho. Leonor Suárez sitúa el origen de este movimiento en Tove Stang Dalh.

17. CARRERAS, M. : op.cit., p.113. La autora señala que Carol Gilligan basó sus argumentos sobre la distinta capacidad de razonamiento moral entre el hombre y la mujer en una serie de encuestas que realizó entre jóvenes universitarios sobre el dilema que se plantea en el caso Heinz. Heinz era un hombre pobre cuya mujer estaba gravemente enferma y que seguramente moriría 
experimentos, sostiene que existen dos tipos de moral igualmente racionales, la masculina y la femenina, cada una de ellas con sus específicas y propias fases de maduración ${ }^{18}$ La teoría de Gilligan podría resumirse en la existencia de dos éticas, la femenina y la masculina, siendo la primera de ellas una ética del cuidado y la responsabilidad, y la segunda una ética de principios.

Gilligan cuestiona el modelo de Kohlberg de desarrollo del juicio moral negándole la pretensión de universalidad del modelo por las dificultades que plantea dar cuenta de los juicios y del sentido del propio yo que tienen las mujeres ${ }^{19}$. Según Gilligan, las mujeres se explican a sí mismas en términos de conexión con otros y no en términos de separación ${ }^{20}$.

si no tomaba una medicina carísima que no podía pagar. Gilligan preguntaba qué harían en el lugar de Heinz si el farmacéutico se negara a darles el medicamento. La respuesta era diferente según se tratara de hombres y mujeres. A raíz de este experimento, Gilligan elabora la teoría de que no hay una única vía en la maduración moral del ser humano, sino dos: la del hombre y la mujer, y en eso se opone a la psicología tradicional representada por Piaget y Kohlberg. BENHABIB, S.: "Una revisión del debate sobre las mujeres y la teoría moral», en Isegoría, $n^{\circ} 6$ (noviembre 1992), traducción de Carlos Thiebaut, pp. 37-65. Acerca de Carol Gilligan señala: «...a raíz de la publicación de su libro In a different Voice, se inició un debate sobre feminismo y teoría moral, al igual que ocurrió con otras obras, esta puso de relieve la llamada de atención que supone la cuestión de las mujeres, desde dentro del discurso científico establecido. Cuando las mujeres entran a formar parte del cuadro, ya sea como objetos de la investigación de las ciencias sociales o como investigadoras, se tambalean los paradigmas establecidos. Se cuestionan la definición del ámbito de objetos del paradigma de la investigación, así como sus unidades de medida, sus métodos de verificación, la supuesta neutralidad de su terminología teórica o la pretensión de universalidad de sus modelos y metáforas.», p. 38.

18. J.A. GARCÍA AMADO en ¿Tienen sexo las normas?( op cit.) recoge una síntesis del trabajo de la autora. "... no hay una única vía y una única secuencia de etapas en la maduración moral del ser humano, como sostendría Kohlberg, sino dos: la masculina y la femenina. Y así, cuando Kohlberg distingue sus famosas seis etapas, la última de las cuales pertenece al nivel postconvencional y equivale a pensar los problemas morales a la luz de principios de justicia universales reflexivamente madurados, estaría universalizando un modelo de razonamiento moral que es propio únicamente de una parte de la humanidad, la masculina. Porque lo que Gilligan sostiene haber demostrado con sus conocidos experimentos es que si hombres y mujeres responden con planteamientos distintos a idénticos dilemas morales no es porque, como se seguiría de la aplicación de las categorías de Kohlberg, se encuentran respectivamente en estadios distintos de maduración o capacidad de racionamiento moral, sino debido a que participan de modos intrínsecamente distintos de comprender y afrontar los problemas morales. La voz de la moral racional no sería esa única voz que Kohlberg retrata en sus diversas modulaciones, sino que habría dos voces, dos tipos de moral igualmente racionales; en el fondo, dos morales: la masculina y la femenina, cada una con sus específicas y propias fases de maduración.»

19. Como señala S. BENHABIB en Una revisión al debate... (op cit), esta crítica era compartida por otros autores como Taylor y Walzer, que cuestionaban que los juicios morales referidos a la justicia pudieran aislarse tan claramente del contenido cultural de las concepciones de la vida buena. Había pues, señala la autora, una convergencia entre el tipo de crítica feminista de Gilligan ante el universalismo Kantiano, y las objeciones que formulaban estos autores (p. 39).

20. GARCIA AMADO, J.A: ¿Tienen sexo las normas?, op. cit., p. 14.

"Según Gilligan, el ideal de persona madura en Kohlberg presupone una persona que se define a sí misma como un individuo separado de los otros y que intenta determinar de un modo lógico cuáles son sus derechos, dentro de los límites de la no interferencia con los derechos de otras personas. Esta concepción es, en opinión de Gilligan, masculina. Las mujeres se explican a sí mismas en términos de conexión con otros y no en términos de separación. Se experimentan 
La teoría formulada por Gilligan que entronca directamente con el feminismo de la diferencia ha sido muy criticada ${ }^{21}$; sin embargo es importante resaltar que ha resultado extremadamente útil para poner de manifiesto que, en el campo de los valores, las mujeres han sido excluidas y por lo tanto la universalidad con la que se presentan los principios y valores ilustrados es una falsa universalidad.

Sin embargo, el problema de la posición mantenida por la autora reside en que, llevando su teoría hasta las últimas consecuencias, se parte de la concepción moral de la existencia de dos éticas diferentes y separadas, y la aceptación de este presupuesto imposibilita el establecimiento de valores universales.

Que la mujer ha sido excluida de la formulación de los valores que conforman la modernidad y por tanto del estado y todos sus instrumentos, incluido el derecho, parece un hecho incuestionable; el problema es desde qué perspectivas se aborda la crítica a esta concepción falsamente universal, estableciendo este nuevo sujeto -universal- que integra las vindicaciones del género-sexo femenino.

\section{Modelos de revisión feminista}

$\mathrm{Si}$, tal y como se ha afirmado anteriormente, las normas tienen interiorizados unos valores que responden a unos parámetros identificados con lo masculino, la cuestión se sitúa en cómo debe abordarse la elaboración de las normas para favorecer la igualdad de las mujeres. Siguiendo la propuesta de Leonor Suárez 22 podemos afirmar la existencia de dos modelos, básicamente, para afrontar esta realidad.

El primer modelo responde a la idea de que las normas, o bien discriminan directamente a las mujeres, o bien -sin discriminarlas formalmente- en la práctica producen un resultado material que las sitúa en una posición de inferioridad respecto de los hombres. En ambos casos es necesario cambiar las normas, y la modificación presupone que previamente se ha establecido una previsión acerca de las consecuencias que la modificación va a producir sobre el hecho que se pretende cambiar.

Una norma que discrimina a las mujeres bien formal o materialmente es porque parte de un modelo sobre el cual se establece un tertium comparationis, la discriminación es con respecto a alguien y ese alguien en el caso del derecho es

y describen a sí mismas como insertas en una red de relaciones. Con esta diferente concepción se llega a una diferente comprensión y elaboración de los problemas morales: éstos no son construidos en términos de resolución de conflictos causados por el conflicto entre derechos, sino en términos de averiguar la respuesta responsable y atenta a las necesidades de ayuda de personas concretas».

21 En lo referente a las numerosas críticas vertidas a la teoría de Gilligan, tanto Seyla Benhabib como Juan Antonio García Amado las reflejan en sus artículos; aunque cada uno se posiciona a favor de alguna de ellas, no dejan de reconocer la importancia de esta teoría en lo que supone de amplitud del paradigma de investigación en este campo.

22. SUÁREZ, M. Leonor: Teoria..., op.cit. , p. 186. 
el hombre. La mujer sufre una discriminación respecto del hombre, que disfruta de una mejor posición a la que la mujer debe poder alcanzar, pero el modelo en sí mismo no se cuestiona. Lo que realmente está cuestionando es el instrumento, la norma, que no ha sido elaborada con la suficiente corrección para que el resultado sea igualitario, esto es que la situación de los hombres y las mujeres sea equiparable.

Si el modelo sigue siendo el mismo, las normas para poder alcanzar un resultado igualitario deberán tener en cuenta que las mujeres están en una situación diferente e inferior a la de los hombres, debido a razones históricas que no viene al caso señalar y que las ha situado en una realidad de desigualdad grupal ${ }^{23}$; en atención a esta discriminación las normas deberán adoptar medidas que favorezcan temporalmente (denominadas acciones positivas) a las mujeres para que puedan alcanzar el estatus del que ya disfrutan los hombres.

Este modelo de solución frente a la discriminación de la mujer es criticado fundamentalmente por el denominado "feminismo de la diferencia», que lo ha considerado como un mero asimilacionismo, esto es, absorción y convalidación implícita del modelo con el que se compara.

El segundo modelo parte de la base de que la discriminación de las mujeres es una discriminación estructural determinada por el modelo social establecido a partir de la configuración del sexo-género, es decir de la atribución de consecuencias sociales a las diferencias biológicas de los hombres y las mujeres. El género masculino es el modelo que preside la elaboración normativa, la aplicación de norma, el criterio de coactividad, el conocimiento y la discusión académica; se trataría de promover un cambio estructural del modelo institucional, una nueva opción normativa alejada de los parámetros de generalidad, abstracción, imparcialidad y neutralidad, tanto por lo que se refiere a la creación normativa como por lo que respecta a su aplicación, amparado todo ello en un giro de la mentalidad académica oficial y característicamente femenina ${ }^{24}$.

La autora plantea objeciones a los dos modelos: respecto al primero, señala que tendría que abordar una casuística relacionada con la situación de discriminación concreta que sufren las mujeres para poder así elaborar las normas que solucionara el conjunto de las discriminaciones, pero el problema reside en la dificultad de llegar a acuerdos acerca del análisis crítico y la reconstrucción del derecho.

En relación con el segundo, la pretensión de un cambio estructural presupone la existencia de un modelo de mujer característicamente diferente al del hombre en cuanto diseñador del marco jurídico-político y ello precisa aceptar la existencia de una esencia de mujer capaz de determinar cuál será el nuevo modelo.

23. BARRERÉ UNZUETA, M. :"Problemas del derecho antidiscriminatorio: subordinación versus discriminación y acción positiva versus igualdad de oportunidades", Revista Vasca de Administración Pública, 60 (2001), p.152.

24. SUÁREZ, M. Leonor: Teoría feminista.., op cit, p. 191. 
Para la autora, ambas posiciones no son excluyentes y sitúa el problema en la determinación del procedimiento más adecuado para alcanzar acuerdos públicos justificados que se plasmen a nivel legal; para llegar a ellos propone el método habermasiano de la acción comunicativa, aunque el núcleo de su propuesta reside en los postulados ilustrados, igualdad, autonomía y racionalidad de los individuos con independencia de los contingentes históricos particulares $^{25}$ (concepción dicursiva como clave de la actuación político-normativa de la liberación de la mujer).

La igualdad ante la ley constituyó en su día una reivindicación esencial del liberalismo y sigue siendo hoy un elemento esencial del Estado Constitucional y no porque la igualdad constituya el contenido necesario, aunque no suficiente, de la idea de justicia, sino porque es una parte esencial del Estado Constitucional, presente ya en el triple lema revolucionario. En efecto, el Estado Liberal se articula en torno a la noción de ciudadanía: estatus común a los miembros de la comunidad política, precisamente por su cualidad de tales, y que sólo puede lograrse en el supuesto de que la ley sea la misma para todos sus miembros, hecha por un mismo legislador, administrada por una misma judicatura, teniendo como destinatarios a los miembros de la comunidad, sin acepción de estamentos, clases o personas, para lo cual debe ser necesariamente norma de carácter general. Pero esta igualdad no persigue la igualdad material entre los miembros de esta sociedad, precisamente porque el Estado Liberal descansa en la separación entre el Estado y la Sociedad Civil, correspondiendo la igualdad a la esfera del Estado (lo público) y no a la de la sociedad civil (lo privado).

La ley que debe asegurar y garantizar la homogeneidad del status civitatis, negativamente exige la exclusión de normas de grupo, estamento o clase por lo que debe hacer abstracción de las desigualdades materiales que subyacen al estatuto de ciudadanos. Ello no comporta la prohibición al legislador, y a la ley, de establecer diferencias, por el contrario puede tomar en cuenta las diferencias materiales que surgen del funcionamiento autónomo de la sociedad civil, del libre juego de las fuerzas sociales, en tanto en cuanto sus normas establezcan la ordenación de la propia sociedad civil. De esta forma, en todo lo que concierne al derecho privado pueden establecerse y son legítimas -en esta autonomía de lo privado respecto de lo público (donde es preceptiva la igualdad)- diferencias

25. Frente a estas propuestas (SUÁREZ, pp. 193, 197 y 198), afirma que el modelo discursivo liberal es el que ofrece los recursos mas adecuados a la filosofía política para la formulación de una construcción racionalmente justificable de la justicia político-institucional, o, si se prefiriere, de la legitimidad moral y política del entramado político jurídico de cada sociedad particular (193). El núcleo de su propuesta se concreta en que la filosofía política-liberal no integra una única, homogénea y unitaria tradición, sino que la misma definiría de forma muy abstracta un núcleo de pensamiento que será desarrollado de forma diversa y, en ocasiones, incluso contradictoria. Una vez delimitado el núcleo esencial de la propuesta liberal, es preciso someterlo a una crítica a través de una propuesta discursiva integradora en la que todos los individuos son participantes potenciales del discurso. Se parte de un acuerdo universal acerca de la igualdad, autonomía y racionalidad de los individuos independientemente de los contingentes históricos particulares. 
que, como en el caso de la familia, matrimonio y filiación, son naturales, congruentes o tradicionales.

No obstante, es necesario el manejo de la categoría mujer, como categoría aparentemente universal y esencializada, a los solos efectos instrumentales con el objeto de favorecer el esclarecimiento de las condiciones que han conducido a los integrantes de un determinado grupo a someterse a definiciones restrictivas de sus posibilidades de definición y desarrollo. Dado que si no se parte de esta premisa el derecho, incluido el derecho antidiscriminatorio, solamente podría intervenir cuando se produce una discriminación concreta, esto es una conducta individual imputable, pero se dejan fuera del análisis todas las secuencias anteriores que influyen de una manera determinante en la adopción de una decisión concreta sobre la que pesa la obligación de constatar y por tanto probar un ánimo discriminatorio.

El modelo sobre el que deben revisarse las normas desde una crítica feminista no puede identificarse, a nuestro entender, exactamente con ninguno de los dos modelos, los que representan el hombre y la mujer, porque el modelo mujer existe y es una categoría que ha utilizado el patriarcado para asignar unas funciones que no han sido consideradas como objeto de regulación en el ámbito jurídico-político institucional y por tanto situadas en un nivel de inferioridad. Estos dos modelos deben incorporarse como tales a la regulación jurídico institucional pero desvinculándolos del sexo-género, esto es, dos modelos con igual consideración con independencia del sexo que los realice, porque no podemos olvidar que estos dos mundos siguen vigentes y probablemente continúen durante mucho tiempo, y son los dos modelos que responden al mundo de la producción y al mundo de la reproducción.

En este sentido, nuestra posición se identificaría con aquellas posturas que cuestionan la universalidad de los valores y las normas por entender que son parciales y responden al modelo no universal (sólo incorporan el modelo masculino). Esta parcialidad debería ser implementada ${ }^{26}$ con el modelo femenino. Aunque estas categorías tengan una finalidad exclusivamente instrumental (siguiendo a Llanos), deberían servir para redefinir la nueva universalidad no excluyente e integradora de las diferentes individualidades, sujetos racionales, iguales y dotados de la máxima autonomía, siguiendo con la tradición ilustrada de mantener valores universales.

26. En este mismo sentido, J. A. GARCÍA AMADO en ¿Tienen sexo las normas? (op. cit) señala que la teoría de Seyla Benhabib no es «... un cuestionamiento radical del principio de universalización, sino la constatación de su necesaria complementación con la toma en consideración de las existencias reales de las personas implicadas en el caso, a fin de que la abstracción no signifique imposición de un único patrón de humanidad y racionalidad a efectos del racionamiento moral, en concreto del patrón masculino». En sus palabras «el reconocimiento de la dignidad y valor del otro generalizado es una condición necesaria, pero no suficiente para definir el punto de vista moral de las sociedades modernas. En este sentido, el otro concreto es un concepto crítico que designa los limites ideológicos del discurso universalista» (pp 20-21). 


\section{III.- LOS ESTUDIOS DE DERECHO DESDE LA PERSPECTIVA DE GÉNERO}

Los datos en relación a los estudios en el ámbito del derecho y género se recogen en el libro Universidad y feminismo ${ }^{27}$, en el que se señala cómo el ámbito del derecho es una materia de poco arraigo en los estudios de las mujeres, a pesar de que a comienzos de los años ochenta era uno de los campos con más aportaciones y a pesar también de los cambios sociales y jurídicos producidos a partir de la aprobación de la constitución, que podían dar lugar a un incremento de estos estudios.

Si nos detenemos en el análisis de los datos reflejados en el mencionado estudio, se puede constatar la existencia de una notable diferencia en la cantidad de registros que se dan en los denominados derecho público y derecho privado a favor del primero, excepción hecha del derecho civil que es el área que, después del derecho del trabajo, tiene más registros. Actualmente, aunque no se tienen datos suficientemente contrastados, se sigue reproduciendo esta diferencia; los ámbitos mas susceptibles de investigaciones relacionadas con la discriminación de las mujeres se sitúan en el derecho público. Así, los estudios de derecho vienen a corroborar la clásica distinción: público - privado, aunque los conceptos público/privado no son totalmente coincidentes con la distinción clásica entre derecho público y derecho privado.

La distinción entre derecho público y derecho privado es la más relevante en la doctrina científica; el primero se caracteriza porque se produce un ejercicio del poder del Estado dirigido a regular la organización y la actividad del mismo y demás entes públicos a la vez que rige en las relaciones entre el estado y los particulares. El derecho privado es el que regula la relación entre particulares, en la que podemos destacar que en esa relación se encuentran en una posición igual.

Las relaciones que regulan tanto el derecho público como el derecho privado se sitúan en la esfera de lo público, por tanto la denominación del derecho como público o privado está referido a la posición que mantienen las partes en la relación jurídica y no al lugar en el que se producen los hechos objeto de regulación; solamente se podría confundir el lugar con los sujetos en el ámbito que abarca los denominados derecho matrimonial y derecho de familia y, ni tan siquiera en estos supuestos, dado que tanto el derecho matrimonial como el de familia regulan las consecuencias del contrato matrimonial o las consecuencias de la filiación, pero no ordenan las relaciones que se desarrollan en el ámbito doméstico porque éste forma parte de la vida privada; en definitiva, son las consecuencias públicas de una relación que se desarrolla en el ámbito de la máxima privacidad.

27. Universidad y Feminismo en España. Situación de los estudios de las mujeres en los años 90, Coordinadora Teresa Ortiz, Colección Feminae, Universidad de Granada, 1999. 


\section{1.- El Derecho Público: las diferentes áreas de conocimiento ${ }^{28}$}

La aprobación de la Constitución y la adaptación del ordenamiento jurídico a los principios y valores constitucionales son los motivos fundamentales que han posibilitado la aparición de los estudios de género, aunque quizá en menor medida de lo que sería deseable. No todas las áreas incluidas en el ámbito del derecho público han desarrollado estudios de género o lo han realizado en la misma extensión. Es verdad que algunas de estas áreas están más relacionadas con la igualdad por la materia que abarcan, o bien porque el investigador o la investigadora tengan una posición proclive a este tipo de estudios, y a ello ha contribuido en gran medida el denominado feminismo académico, que en derecho al igual que en otros ámbitos ha sido el impulsor de estos estudios. Sin embargo cabe señalar que en derecho ha sido el ámbito donde menos investigadoras -y por tanto producción científica- ha habido.

Los estudios de género requieren un nivel alto de compromiso investigador, un plus añadido a la laboriosidad que requiere cualquier investigación, debido en parte a la minusvaloración científica que pesa sobre las investigaciones relacionadas con esta temática y sobre todo en el ámbito del derecho, que adolece de una tradición investigadora en este sentido.

El Derecho Constitucional es una asignatura reciente en nuestras facultades de derecho, tan reciente que nace con la aprobación de la Constitución de 1978.

La igualdad es en la Constitución valor fundamental, principio rector, y abre el capítulo II con el que se inician los derechos y libertades. Así se define en el art. 14 la igualdad ante la ley, prohibiéndose la discriminación, entre otras causas, por razón de sexo; en el art. 9.2 se establece que los poderes públicos deben promover las condiciones para que la libertad y la igualdad del individuo y de los grupos sean reales y efectivas. De esta manera aparece configurada en nuestra Constitución la igualdad ante la ley, denominada igualdad formal, y la posibilidad de llevar a cabo desde el poder acciones positivas que permitan la consecución de la igualdad real, denominada igualdad material.

Podemos decir que estos dos artículos y su relación con otros preceptos de la Carta Magna han sido lugar común de las investigaciones de género en el Derecho Constitucional que, precisamente por ello, están claramente alineadas en su casi totalidad en el planteamiento reivindicativo de la igualdad y promoción de las mujeres. Se parte de la prohibición de discriminación, lo que equivale, por tanto, a admitir desigualdades en el acceso a puestos de decisión o promoción profesional en la función pública y en la empresa privada, e indirectamente se está afirmando su existencia, por tanto es impensable no tener en cuenta el concepto género aunque en alguna ocasión se reclame, por parte de los investigadores, no formar parte del pensamiento feminista.

28. El análisis de las diferentes áreas se realizó en nuestro trabajo Feminismo y Derecho: el derecho a ser sujeto. Universidad y feminismo en España... Op. cit., p. 70. 
En este ámbito la jurisprudencia del Tribunal Constitucional ha dado mucho juego, en un principio porque no aceptaba la diferencia de trato desde la norma como una búsqueda de la igualdad real para las mujeres y se limitaba a aplicar la igualdad entendida como igualdad formal; en un segundo momento porque admitía, al igual que lo han hecho los máximos intérpretes de otros textos constitucionales, las denominadas acciones positivas -sobre todo en el ámbito laboral, admitiendo la discriminación indirecta, introduciendo la inversión de la carga de la prueba- tendentes a equilibrar el mercado laboral eliminando los obstáculos que se han interpuesto históricamente en el acceso de las mujeres al trabajo ${ }^{29}$; lo mismo ocurre en el ámbito internacional, en el que las medidas de acción positiva en el plano laboral han alcanzado el rango de ley convirtiendo en realidad la aplicabilidad de los derechos fundamentales, el derecho al trabajo en este caso, entre particulares, o lo que es lo mismo, la eficacia horizontal de estos derechos de la persona.

En un tercer momento se plantea extender las acciones positivas al ámbito de la participación política, tema todavía no resuelto ${ }^{30}$, y que ha abierto uno de los debates más interesantes de los últimos tiempos en relación a la configuración del sujeto político, el derecho de sufragio, el concepto de soberanía, en definitiva el cuestionamiento del entramado jurídico político acerca de la democracia representativa.

El derecho del trabajo es la disciplina que cuenta con más aportaciones impulsada por el derecho comunitario, que en los últimos años ha sido el ordenamiento que ha tenido una mayor incidencia la idea de igualdad y no discriminación por razón de sexo.

La modernización estructural que sucede en Europa también discurre en España afectando a un cambio en la incorporación de las mujeres al mundo laboral, pero este cambio no modifica los estereotipos diseñados en función del sexo y que en el caso de las mujeres responden a la idea de que las principales misiones de las mujeres son la maternidad, el cuidado del hogar y de sus hijos. Sin embargo, este diseño sólo podía aplicarse a una determinada clase social porque en las poblaciones rurales y en las clases económicamente deprimidas las mujeres han vivido habitualmente la doble jornada toda vez que nadie garantizaba la consecución del estatus de mujer casada, como lo muestran, por ejemplo, las pensiones de orfandad, sólo percibibles por la condición de hijas solteras, sin que todo ello fuera obstáculo para que el modelo ideal impregnara la condición femenina.

29. Como recoge la STC128/1987 «.... En este sentido no debe ciertamente olvidarse que la expresada exclusión de la discriminación por razón del sexo halla su razón concreta, como resulta de los mismos antecedentes parlamentarios del art. 14 de la CR, y es unánimemente admitido por la doctrina científica, en la voluntad de terminar con la histórica situación de inferioridad en que, en la vida social y jurídica, se había colocado a la población femenina...».

30. En estos momentos existen dos recursos de inconstitucionalidad presentados por el presidente del gobierno contra la reforma de las leyes electorales de las CCAA de Baleares y Castilla la Mancha que regulan la paridad y las listas cremallera. 
Estos factores, en lo atinente a lo jurídico, se modifican con la aprobación de la Constitución y la adaptación de la legislación, anterior a la misma, a sus preceptos. No obstante, la presencia de las mujeres en el mundo del trabajo sigue siendo inferior y peor remunerada que la de los hombres y esta diferencia no es fruto de la casualidad sino producida por la existencia de elementos que discriminan, en el ámbito laboral, a las mujeres.

La discriminación en el ejercicio del derecho al trabajo se contempla tanto desde la perspectiva del derecho español como comunitario, aparecen un número importante de normas que modifican las condiciones laborales de las mujeres e intentan en los últimos años y en cumplimiento de las directivas comunitarias conciliar la vida familiar y laboral, entrando de lleno en el quid de la cuestión, esto es, incorporar a la regulación jurídica los obstáculos que se generan en el ámbito familiar y que sólo afectan a las mujeres.

La dinamicidad del derecho del trabajo se ha extendido al ámbito del Tribunal Constitucional y así muchos de los pronunciamientos del tribunal en relación a la igualdad, diferencia de trato, discriminación y acciones positivas tienen su origen en reclamaciones sobre la igualdad en el trabajo ${ }^{31}$.

\section{El Derecho privado: las diferentes áreas de conocimiento}

Dentro del ámbito del derecho privado cabe destacar el Derecho Civil, que es una de las ramas del derecho que regula la relación entre particulares, en la que podemos destacar que en esa relación se encuentran en una posición igual. El derecho civil ${ }^{32}$ regula, por excelencia, las relaciones privadas, y en relación a la parte del derecho civil que regula las relaciones familiares, el denominado derecho matrimonial y derecho de familia, podemos afirmar que rompe el criterio general de que los sujetos de esas relaciones están en una posición igual. Tanto el antiguo Derecho romano como la regulación que se plasmó en el Código de Napoleón utilizó la familia como una célula social bajo la autoridad del paterfamilias. Las mujeres pasaban de la autoridad del padre a la del esposo sin solución de continuidad. La estructura familiar ha perpetuado la tradición más conservadora y ha sido el reducto donde mejor se ha reproducido la ideología patriarcal ${ }^{33}$.

31. Todas estas circunstancias bastarían para justificar la investigación de género en esta área jurídica en orden al número e importancia de los trabajos cuantificados.

32. Los estudios de las Mujeres en las Universidades españolas 1975-1991. Libro Blanco, Ministerio de Asuntos Sociales, Instituto de la Mujer, Madrid 1995, pp. 83-92. Derecho Civil es la materia que le sigue en importancia numérica, ya se destacó en el primer libro blanco la proclividad del Derecho a ocuparse «de modo concreto y explícito de las mujeres en tanto que objetos del Derecho, y por lo general en tanto que objetos vinculados, es decir, sobre todo como parte del matrimonio y de la familia".

33. La presunción de paternidad de los hijos habidos en matrimonio, así como la condición de ilegítima de la prole nacida fuera de él, instituciones como "el hereu», mayorazgo, transmisión de títulos nobiliarios en favor de los hombres que han estado vigentes entre nosotros hasta la aprobación de la Constitución y que, en este último caso, han sobrevivido a ella como la reciente sentencia del T.C. sobre títulos nobiliarios. 
La igualdad que propugna nuestra Carta Magna equipara al hombre y a la mujer en el matrimonio, a todos los hijos en derechos, excepción hecha como se ha dicho, de los títulos nobiliarios, para los que una reciente sentencia del Tribunal Constitucional mantiene la preferencia de los hombres sobre las mujeres como vestigio de las leyes preconstitucionales que regulan la transmisión de estos títulos.

La situación real de los hombres y las mujeres en el matrimonio y la familia dista mucho de ser paritaria debido a la división de roles que se reproduce en el seno de la misma y sitúa a las mujeres en inferioridad de condiciones respecto al desempeño de un trabajo y, sobre todo, en las consecuencias de la disolución matrimonial.

Los temas relacionados con el matrimonio y la familia acaparan la investigación sobre las mujeres en Derecho Civil, a los que hay que añadir la variante de parejas de hecho que, al generar un nuevo modelo de relación estable, presenta situaciones en el límite de la norma pero que dan lugar al nacimiento de derechos o, al menos, expectativas de derechos que es necesario contemplar desde una perspectiva jurídica.

Por ello, estos temas han propiciado investigaciones quizás porque consideran la peculiar situación de la mujer casada o mejor dicho, la influencia negativa que el matrimonio (como institución) ejerce sobre las mujeres en comparación con el cónyuge. 